\title{
Colorectal Surgery Training in the Hong Kong Special Administrative Region and China
}

\author{
Joe King Man Fan ${ }^{1,2}$, Zhonghui Liu ${ }^{1}$ \\ ${ }^{1}$ Department of Surgery, The University of Hong Kong - Shenzhen Hospital, Shenzhen; ${ }^{2}$ Department of Surgery, Li Ka Shing Faculty of \\ Medicine, The University of Hong Kong, Hong Kong Special Administrative Region, China
}

Until 1st July 1997, Hong Kong was under the governance of the British Government; therefore, the British system of education was followed. After internship, 7 years of general surgical training is required to obtain registration and fellowship qualifications of the College of Surgeon of Hong Kong and Edinburg. After having become a specialist in general surgery, the surgeon could choose to specialize in colorectal surgery with an additional 3 to 5 years of specialist training in an accredited centre and 6 months of overseas training with subsidies. On the contrary, China has more than 600 medical schools, and students can enroll in different programs to become a medical practitioner. Despite a great discrepancy exists in the quality of teaching and supervision but there are comprehensive regulations governing the accreditation of hospitals, credentialing of operations, medical records, etc. to ensure medical and patient safety. Vast amounts of resources are being invested to strengthen the quality and to advance the technology used in patient care, not only by supporting basic and clinical research but also by providing extra resources to "import" experts and help develop services with clinical excellence. To accomplish this, the aim of the "three fames project" with a 5-year funding of 3 million United States dollar is to invite overseas experts to help build medical teams in specific areas. Due to its huge population (more than 1.3 billion people), China is a country full of potential for development in clinical research, collaboration, knowledge exchange, and the provision of premier medical services.

\section{Keywords: Hong Kong Special Administrative Region; China; Surgical training; Healthcare reform; Healthcare economy}

\section{INTRODUCTION}

\section{Medical System in the Hong Kong Special Administrative Region}

With the historical background of having been a British Colony, the medical healthcare system in the Hong Kong Special Admin-

Received: December 15, 2017 - Accepted: May 28, 2018

Correspondence to: Joe King Man Fan, MBBS, MS, FRCSEd

Room K445, Block K, Queen Mary Hospital, Pokfulam, Hong Kong Special Administrative Region, China

Tel: +852-22554763, Fax: +852-28728425

E-mail: drjoefan@hku.hk

ORCID code: https://orcid.org/0000-0001-6604-2295

\section{- Part of the information contained in this paper was presented at the International Colo-Rectal Symposium organized by Korean Society of Coloproctology and held in Seoul in 2017.}

(C) 2018 The Korean Society of Coloproctology

This is an open-access article distributed under the terms of the Creative Commons Attribution NonCommercial License (http://creativecommons.org/licenses/by-nc/4.0) which permits unrestricted noncommercial use, distribution, and reproduction in any medium, provided the original work is properly cited. istrative Region (HKSAR) mainly follows the United Kingdom's (UK's) National Health Service system, with most of the cost being covered by the Government; no national health insurance scheme has ever been implemented in the HKSAR. More than $90 \%$ of patients are treated in a mature system of public hospitals that are centrally managed by the Hospital Authority (HA) of the HKSAR; those facilities in Hong Kong receive about 10 billion United States dollar (USD) every year to provide healthcare services-from primary health care to advance medical services like transplantation and robotic surgery. The average cost to the patient is only about $20 \mathrm{USD} /$ day, regardless of the drugs administrated or the procedure performed [1]; the remaining cost is completely subsidized. As all costs are basically absorbed by the government of the HKSAR, no national insurance scheme to cover medical expenses has ever been implemented. However, because of the increasing cost of medical services, a comprehensive national health insurance system may be needed in the future, and currently the feasibility of such a system is being explored and discussed. In general, all medical healthcare personnel receive a 
fixed salary, regardless of the workload or the services provided. Regular funding is provided for renewal and purchase of equipment, but the previous utilization rate of hardware is not considered as a prerequisite for purchasing new equipment; therefore, the budget is allocated according to clinical excellence and patient care instead of pure cost. As the funding of the healthcare system is based on "socialism," the driving force for a medical team is mainly satisfactory patient-centered care and academics, providing high quality services based on the philosophy of Hippocrates. Despite the high quality of the care provided the healthcare system in the HKSAR is being criticized, in general, for having low efficiency.

\section{Medical system in China}

On the other hand, in Mainland China, according to national policies, all hospitals are owned and funded by the Government of China. However, all hospitals should maintain their own balanced budget and must submit their yearly financial plan to the regional/central government for approval. To achieve highly efficient healthcare, all medical personnel receive a basic salary from the government plus a significant bonus based on their hospitals' income and their performance. Apart from the capital for manpower resources, hospitals must reserve a portion of their budgets for regular renewal and replacement of equipment for services. The planning and implementation of a financial budget is vitally important in the medical system in China to maintain the system's ability to provide adequate care for China's large population and to manage the patient load. The medical system in China is more capitalistic, valuing highly efficient work and having a high driving force from monetary return. As a result, great discrepancies exist in the qualities of the healthcare provided by different centers.

\section{UNDERGRADUATE AND POSTGRADUATE TRAINING IN HKSAR AND CHINA}

\section{Undergraduate and postgraduate training in the HKSAR}

Two medical schools are located in the HKSAR - the University of Hong Kong, which was founded in 1887 and was previously named the Hong Kong College of Medicine for Chinese [2] and the Chinese University of Hong Kong, which has been in existence since 1977. The 2 medical schools in the HKSAR graduate about 500 medical professionals every year to serve local populations. Because the 2 institutions have adopted similar approaches to medical teaching, assessment and internship, and basic knowledge, the standards that must be met by the medical students in order to graduate and the qualifications of the newly graduated doctors are the same from both institutions. After 5 years of undergraduate medical training and graduation from the University, the new doctors have the privilege to work in public hospitals in the HKSAR under a provisional registration for a 1-year supervised internship before a full license is issued for independent practice in the region [3].

Postgraduate training starts immediately when graduates pursue a career in a surgical field after internship. The training syllabus of the College of Surgeon of Edinburg, with logbook, basic courses, research requirements, and mentorship, is followed. Membership and fellowship examinations are held in conjunction with the Hong Kong College of Surgeons and the College of Surgeons of Edinburgh; therefore, recognition is obtained from both colleges by taking one conjoint examination in Hong Kong. Postfellowship specialty training is provided in centers accredited by the Hong Kong College of Surgeons, and the trainer-to-trainee ratio is fixed to ensure training opportunities. Fellows must satisfy preset criteria by end of their 2-year specialty training before they can function as a specialist in a particular field and be eligible to apply to be a trainer [4]. A program provided and supported by the Hospital Authority, the University, and the College of Surgeons Hong Kong allows qualified doctors to apply for paid professional leave for 3 to 6 months to work at an overseas center to enrich their clinical and research experiences.

\section{Undergraduate and postgraduate training in China}

China has 33 provinces, a population of over 1.3 billion, and more than 600 medical schools that provide different medical training for students to become medical practitioners: a 5-year bachelor's degree, a 7-year master's degree, or an 8-year doctoral degree. Despite the discrepancy in undergraduate training, medical students in China can obtain a license to practice after 5 years of study and successful performance on an examination. However, the higher the qualifications they obtain, the greater is the potential for their subsequent career path.

In general, after the medical students have completed the standardized residency program [5], they undergo basic and advanced training programs in their own hospitals and take local examinations in order to be promoted to senior resident from resident ( 5 years), attending surgeon from senior resident (5 years), etc. The whole training program is under the governance of the Ministry of Health and is regulated by the local government unit and the hospitals. The average training period for each level is about five years, and subspecialty training starts at the level of senior resident (Fig. 1). Strict rules, based on seniority, govern the level of surgery that surgeons can perform. For example, junior residents are only allowed to perform minor operations like hemorrhoidectomies, anal fistulectomies etc. whereas only senior consultants can perform complex operations such as a low anterior resection or newly developed procedures such as a transanal total mesorectal excision/endoscopic submucosa dissection. Overriding of authorization, in general, is not allowed, and a penalty may be incurred if that should happen; when a medical incident occurs, the surgeon and his or her unit should bear full responsibility. The regulations on the governance of surgeons are clear-cut, but lack flexibility, especially when talented surgeons have to wait until they are qualified to perform procedures listed 


\section{PATHWAY TO BECOME A COLORECTAL SPECIALIST}

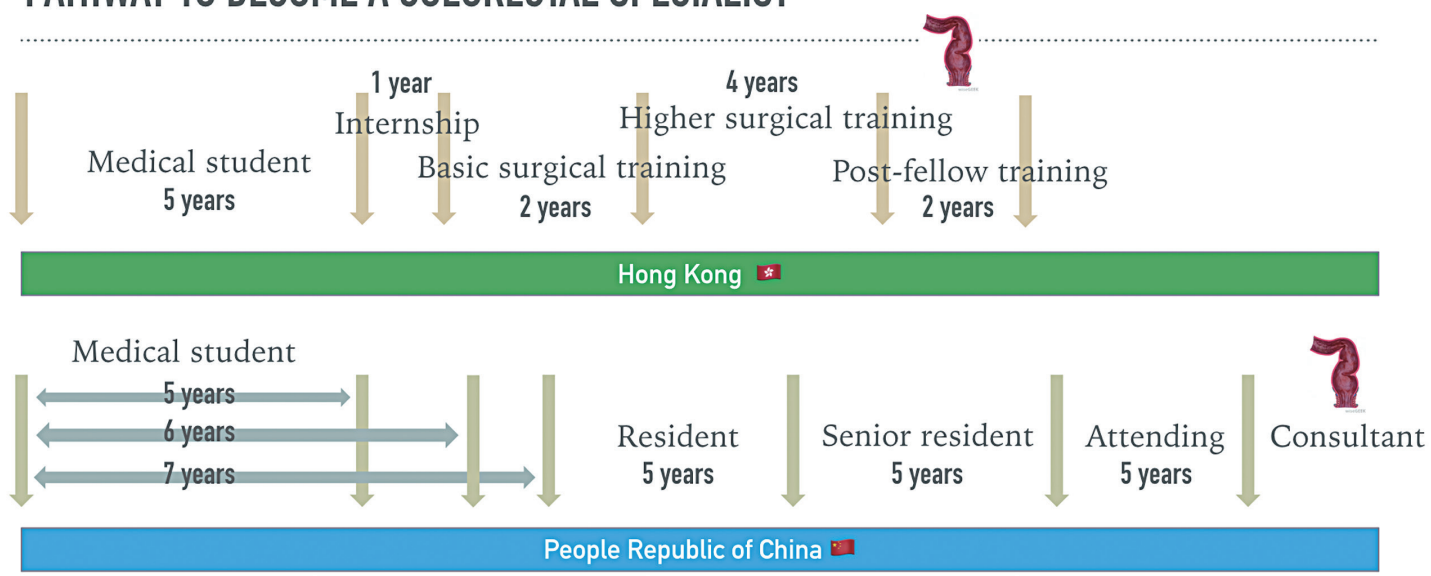

Fig. 1. Schematic diagram comparing the timelines of surgical training in the Hong Kong Special Administrative Region and Mainland China.

as beyond their competence level. Due to the large number of centers providing postgraduate training and the lack of standardized training modules, great discrepancies exist in the quality of teaching and supervision. Nevertheless, comprehensive rules and regulations are in place to govern the accreditation of hospitals, credentialing of operations, medical records, etc. to ensure medical and patient safety.

\section{Research requirement}

Trainees in Hong Kong are required to conduct clinical or basic research as part of the requirement of fellowship training [6]. In addition, they are encouraged to advance their academic achievement further by enrolling for a Master's Degree in Medical Science, a Master of Surgery, etc. After the medical professionals have become fellows of the College, publication or research is no longer a mandatory requirement unless they are working in an academic unit or in a university. However, in China, research and publication are mandatory for promotion. Therefore, throughout their careers, Chinese surgeons are eager to have their manuscripts published; unfortunately, most of those manuscripts are in Chinese. Language is still a major barrier to Chinese surgeons interacting with the international medical society.

\section{REFORM OF THE MEDICAL SYSTEM IN CHINA}

With the huge population in China, the healthcare system needs to be affordable and efficient. The charges for medical services are standardized and are mostly reimbursed via a national insurance scheme [7]. However, the charge set is well below the operating cost of a hospital: e.g., the average consultation fee is about 2 USD and the average cost of a laparoscopic colectomy is about 150 USD [8]. The reason is to limit the medical expenses that the hospitals can charge so that citizens can enjoy relatively low-cost

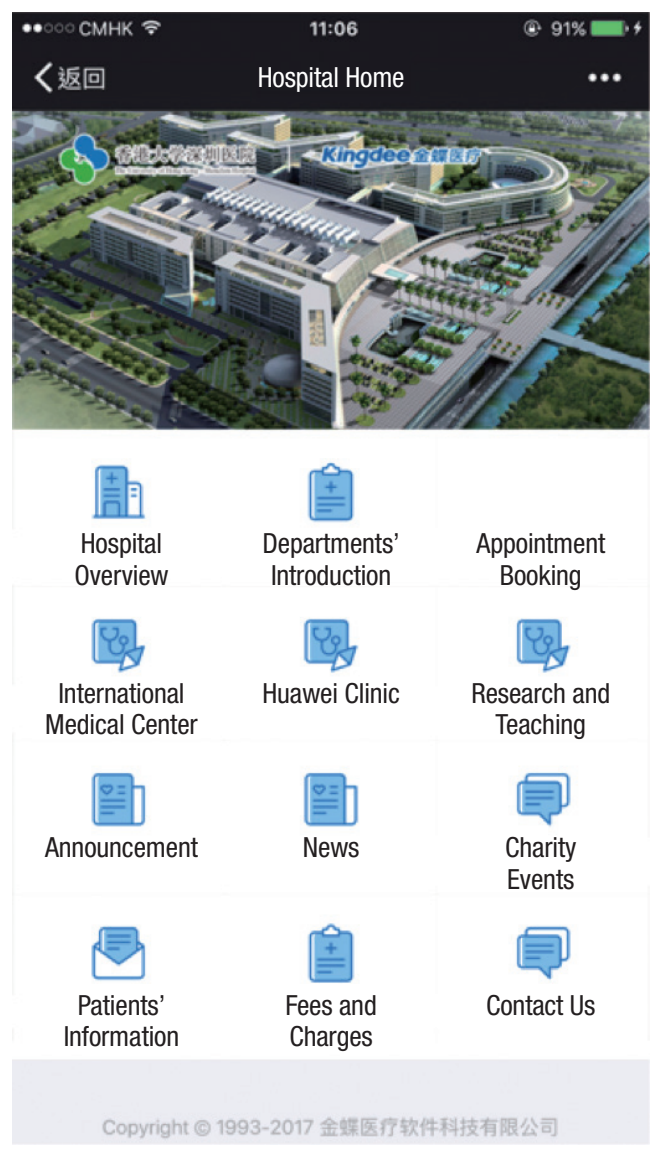

Fig. 2. "Wechat" page for hospital promotion, including basic information on the hospital, introduction to its departments and specialties, private clinic, health check clinic, etc.

medical care. On the other hand, every hospital in China must maintain a balanced budget in order to survive; therefore, overin- 


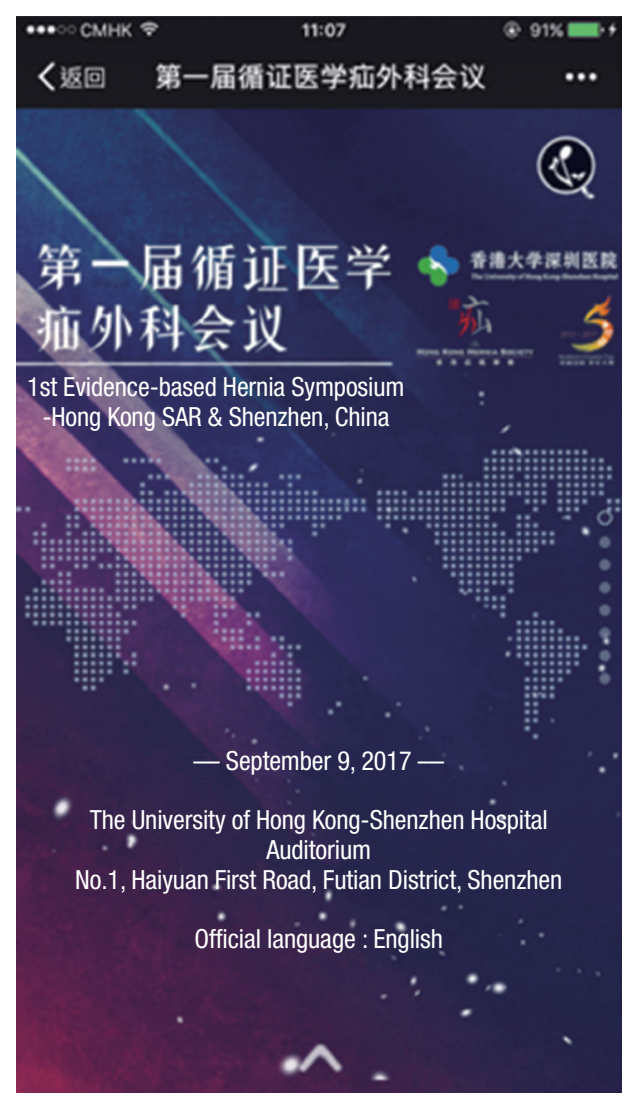

Fig. 3. "Wechat" platform for promotion of academic events: the 1st Evidence-Based Hernia Symposium - Hong Kong Special Administrative region \& Shenzhen, China, held in The University of Hong Kong-Shenzhen Hospital in September 2017. (English was the official language of the event.)

vestigating, overprescribing, and overtreatment are major problems in the healthcare system. The Government of China is now making tremendous efforts to rectify such problems by placing limitations on profits that can be made by selling medications (no surcharge can be imposed) [9] and on the use of consumables (can only be marked-up by $15 \%$ of the purchase price, in general) and by strictly prohibiting any kick-backs or income that is outside the scope of state supervision and control, etc.

\section{Application of information technology in healthcare}

With advances in information technology, healthcare providers, patients, and doctors in this modern era are communicating via instant messaging, in which a program called "Wechat" is popular in China and the rest of the world [10]. Instead of being only a simple instant messaging program, it provides a platform with a broadcasting function for continuous medical education, patient education, promotions of medical activities, etc. In addition, patients can make consultation appointments and electronic payments for the hospital fees and can check their laboratory and test

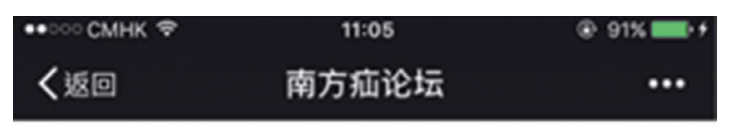

We can create a pre-peritoneal space and insert the laparoscopic ports in the midline by using blunt dissection with a laparoscope, which is most commonly adopted approach. Bilateral insertion of laparoscopic ports like TAPP in the pre-peritoneal space is slightly more complicated, but leads to an easier repair of a bilateral inguinal hernia. Also, we prefer that ports be inserted in the midline and on the lateral side. The ports were inserted in a triangular manner, and the two operating ports are on opposite sides of the camera port; this approach will avoid the "chopsticks" effect and results in a more ergonomic laparoscopic surgery.

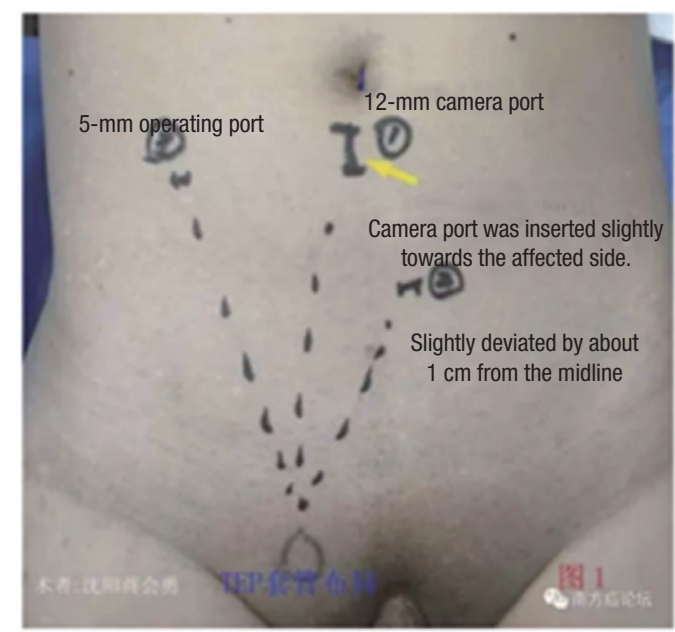

Some have reported the pre-peritoneal insertion of laparoscopic ports in a triangular manner. Such an method uses laparoscopic instruments as a railroad and guides the insertion of laparoscopic port after creation of the pre-peritoneal space. Here, the author describes his own preferred method: the reverse insertion method. The author first reported this approach at the Southern Hernia Congress held in Fuzhou in 2015.

Fig. 4. "Wechat" platform for sharing of medical knowledge. This shows the laparoscopic ports of insertion for Totally Extra-peritoneal Hernioplasty.

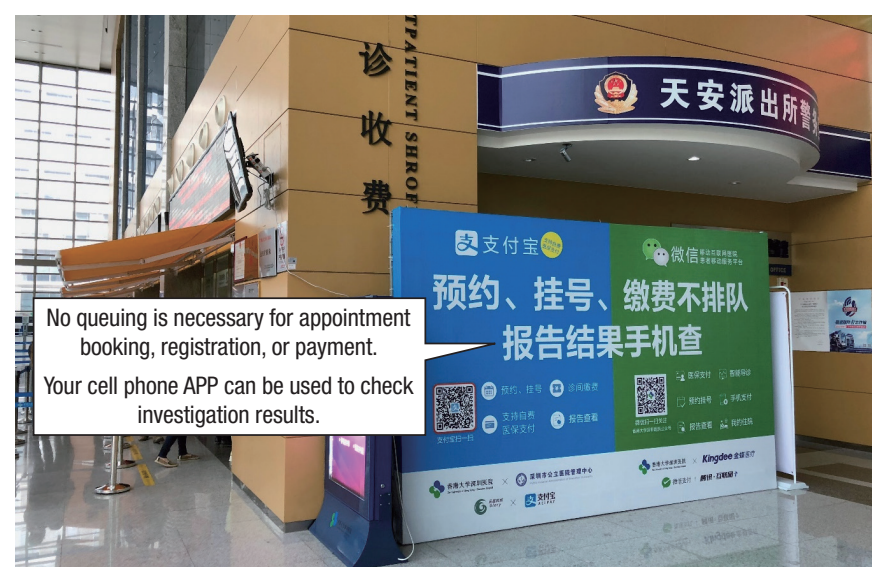

Fig. 5. Promotion of the use of electronic payment at the hospital, the University of Hong Kong-Shenzhen Hospital, Shenzhen, China. The two largest electronic payments - Alipay (blue) and Wechat pay (green) can be used in most hospitals in China. 


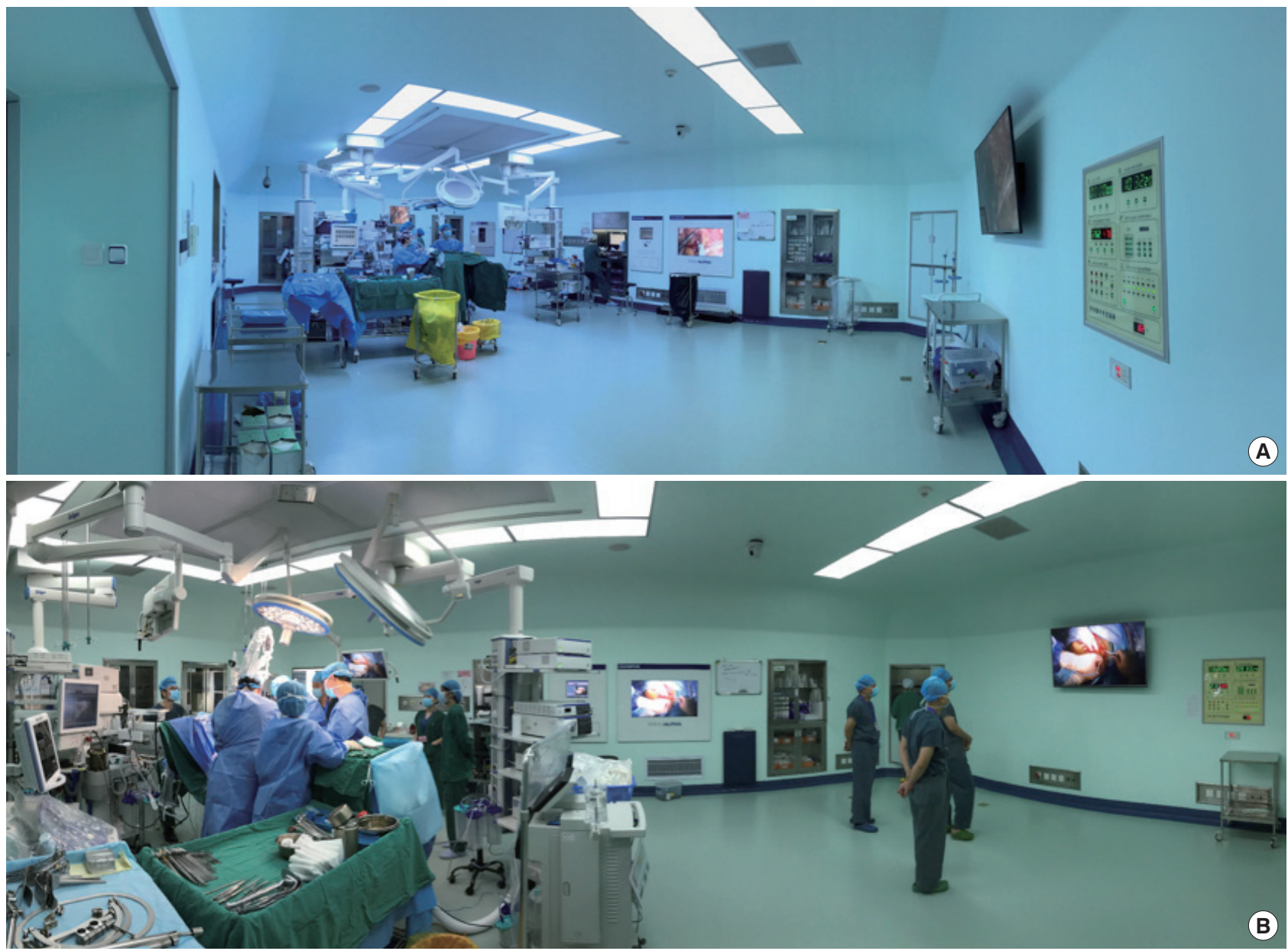

Fig. 6. Ninety square meter Minimally Invasive Surgery (MIS) theaters to provide robotic services, the University of Hong Kong-Shenzhen Hospital, Shenzhen, China: view from the entrance to the theater (A) and view from a side window of the theater (B).

results via the program in seconds (Figs. 2-5). Advanced information technology allows hospitals to become "smart hospitals" and to provide their patients with the best medical experience.

\section{Health care planning in Shenzhen, China}

Shenzhen, a special economic zone and a pioneer of reform in China, is a rapid growing city in terms of finance, city planning, facilities, buildings, etc. To the contrary, the scale and the quality of healthcare in the city is lagging far behind that in major cities such as Beijing and Shanghai. In order to improve the healthcare system in the region, the Shenzhen Government, according to the 13th 5-year plan of the country, is going to provide 25,000 more hospital beds in 5-years' time. Billions are being spent to build hospitals, to provide additional hospital beds and medical training, etc. (Figs. 6-8); nevertheless, the city is still facing the problem of an insufficient number of medical healthcare providers because only one medical school capable of training fewer than 40 doctors a year is located in the city. Therefore, most of doctors must be re- cruited from other regions of China. Apart from quantity, the quality medical care is as vitally important as the number of hospital beds added; for that reason, the Shenzhen Government, by using various subsidies and taxation policies, is actively attracting experts from within and outside China to help establish specialist teams for providing excellent medical care The "three fames project" is one example of such a program for recruiting overseas experts to help develop local teams for specialized services over a period of 5 years with funding up to 2 million USD [11]. The primary hospitals in Shenzhen can submit applications to collaborate with expert teams in China or to collaborate internationally to develop specialty services. The expert teams must be led by National or international experts and provide service for not less than 1 month in a year through collaboration in research, clinical services, supervision, education, knowledge exchange, etc. Upon successful application for a project, the 2 centers' contributions will be recognized, and a yearly funding up to 450,000 USD will be granted for equipping essential facilities and for providing ex- 


\section{Annals of Colorectal Surgery Training in the Hong Kong Special Administrative Region and China}

Coloproctology $\quad \begin{array}{ll}\text { Annals of } & \text { Colorectal Surgery Training in the Hong Man Fan and Zhonghui Liu }\end{array}$

\section{Joe King Man Fan and Zhonghui Liu}

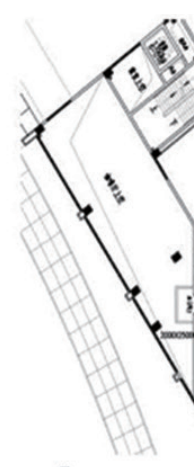

-

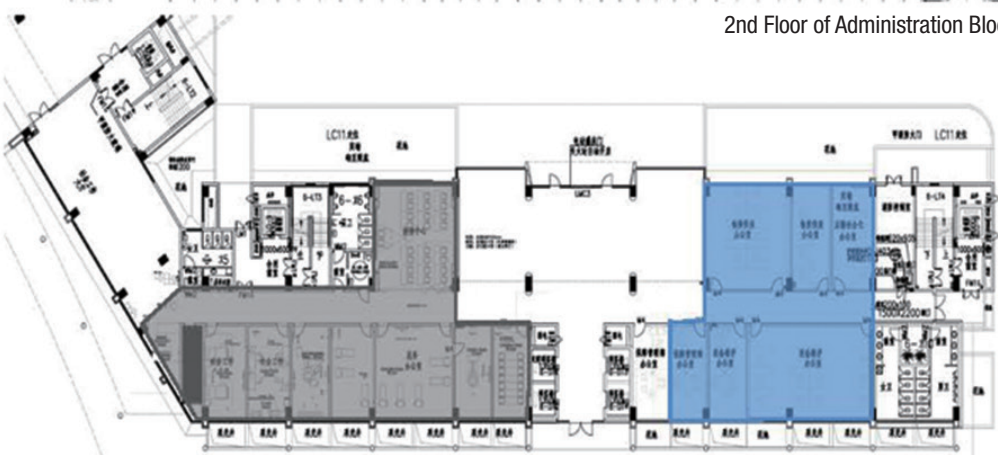

1st Floor of Administration Block

Floor plan

Minimally Invasive Surgery Basic Skills Training Center (dry lab) (completed)

Minimally Invasive Surgery Advanced Skills Training Center (wet lab) Animal Laboratory

Basic Skills Simulation Training Center

OSCE Examination Area

Telemedicine Center

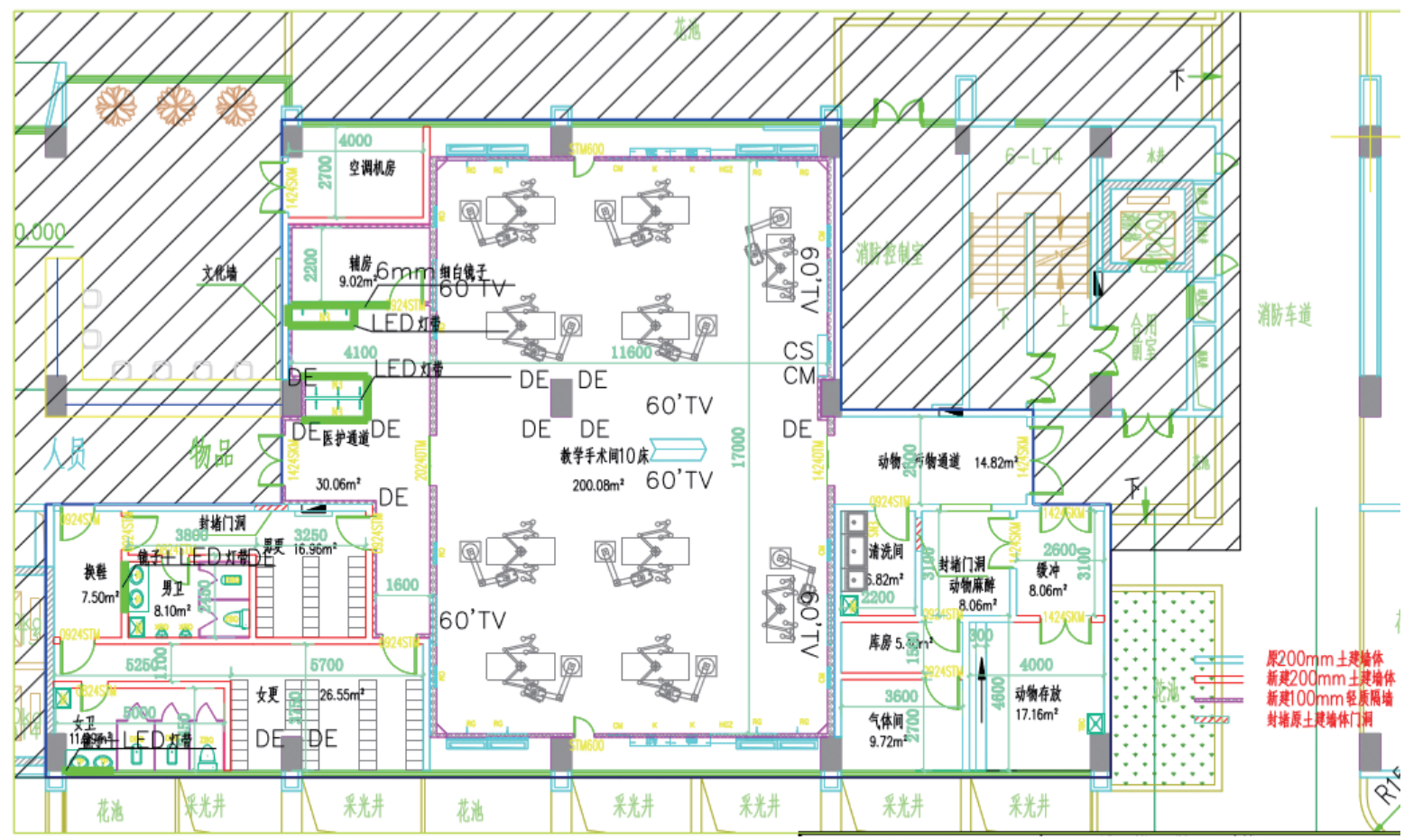

Fig. 7. (A) Second phase of the Clinical Skills Simulation Training Centre with animal dissection facility (1st and 2nd floor), Administration Block, the University of Hong Kong-Shenzhen Hospital, Shenzhen, China: grey, existing skills training center; blue, minimally invasive animal dissection theater; yellow, basic skills training rooms; red, telemedicine center. (B) Second phase of the Clinical Skills Simulation Training Centre with animal dissection facility, the University of Hong Kong-Shenzhen Hospital, Shenzhen, China: detailed layout of the minimally invasive animal dissection theater (equipped with 10 dissection tables). 


\begin{abstract}
Gross Examination:
One piece of tissue with a size of $4.3 \mathrm{~cm} \times 2.5 \mathrm{~cm} \times 2.3 \mathrm{~cm}$, a serous exudate, and a thin, smooth sac wall is seen. Two pieces of tissue were taken for histological examination.

Histological Examination:

The walls of the fibrous capsules were dense, with no epithelial cell lining. Blood vessels were dilated and congested, and focal, isolated, calcified globules were seen, which are compatible with parasitic eggs.
\end{abstract}
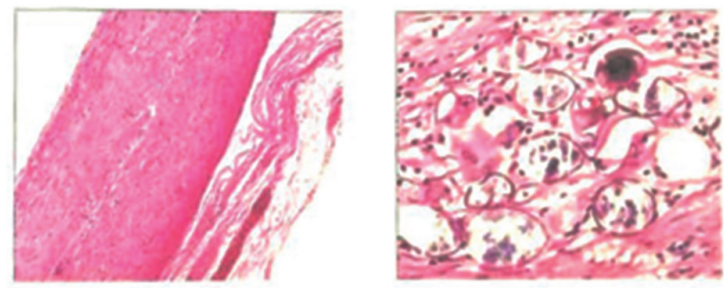

Right GROIN, excision of hernial sac

- Fibrous capsule wall tissue:

- Suggestive of parasite eggs.

Fig. 8. Pathology report showing a rare disease - parasite eggs within an inguinal hernia sac.

penses for conferences, clinical services, etc. With stepwise progress of team development, funding will be continually granted every year. This project can not only help local doctors to advance their professional development and to develop An excellent medical care at international standards but also allow international experts to explore the potential of development in the healthcare industry in China.

\section{POTENTIAL OF HEALTHCARE SERVICES IN CHINA}

The economy in China has been growing exponentially within recent decades, as has the population and patient load. The disease patterns encountered in China are broad and range from traditional disease such as parasitic infections to cancer-related diseases (Fig. 8). One of the reasons for such broad patterns is the significant differences in culture, social status and life styles between the people living in rural areas and those living in urban regions. Such a situation provides an ideal platform for researchers to study the aetiology and epidemiology of common and rare illnesses and to conduct interventional studies that can be completed in a relatively short period of time due to the large sample size.

The demand for medical healthcare is huge, as is the demand for high-quality services. As a large discrepancy exists in the quality of healthcare, patients are asking for high-end services and do not mind paying a higher rate at their own expense. Due to the policies of China's Food and Drug Administration (CFDA), most newly marketed U.S. Food and Drug Administratio-approved overseas medical devices must be initially registered under the CFDA before they can be imported into China, and the usual time from application to approval is longer than 2 years. More- over, some doctors experience language barriers, and the latest technology and skills have not yet been widely adopted in most centers. As a result, some patients choose to be treated in centers of excellence or hospitals outside China in order to be benefit from the latest technology and devices.

\section{CONCLUSION}

Despite the discrepancies in the system of medical training, the Government of China is expending tremendous resources and efforts in healthcare reform to improve the quality of healthcare while at the same time, maintaining a highly efficient system capable of serving China's huge population. This revolution involves opportunities and resources for providing better healthcare services in China to all regions of China.

\section{CONFLICT OF INTEREST}

No potential conflict of interest relevant to this article was reported.

\section{REFERENCES}

1. Hospital Authority. Fees and Charges [Internet]. Hong Kong: Hospital Authority; c2018 [cited 2017 Dec 8]. Available from: http://www.ha.org.hk/visitor/ha_visitor_index.asp?Content_ID= 10045\&Lang=ENG\&Dimension=100\&Parent_ID=10044.

2. University history, the early years [Internet]. Hong Kong: The University of Hong Kong; c2018 [cited 2017 Dec 8]. Available from: https://hku.hk/about/university-history/the-early-years. html.

3. The Medical Council of Hong Kong. Registration of Medical Practitioners [Internet]. Hong Kong: The Medical Council of Hong Kong; c2018 [cited 2017 Dec 8]. Available from: https:// www.mchk.org.hk/english/registration/registration_requirement.html.

4. The College of Surgeon of Hong Kong. Registration for basic surgical training [Internet]. Hong Kong: The College of Surgeon of Hong Kong; c2018 [cited 2017 Dec 8]. Available from: http:// www.cshk.org/cshk.php?page=page\&menupageid $=6066$.

5. Lio J, Dong H, Ye Y, Cooper B, Reddy S, Sherer R. Standardized residency programs in China: perspectives on training quality. Int J Med Educ 2016;7:220-1.

6. The College of Surgeon of Hong Kong. Research project [Internet]. Hong Kong: The College of Surgeon of Hong Kong; c2018 [cited 2017 Dec 8]. Available from: http://www.cshk.org/cshk.ph p? page $=$ page $\&$ menupageid $=5578 \&$ menupageid $=5578$.

7. Ministry of Human Resources and Social Security of the People's Republic of China. Medical insurance [Internet]. Beijing: Ministry of Human Resources and Social Security of the People's Republic of China; [cited 2017 Dec 8]. Available from: http://www. mohrss.gov.cn/SYrlzyhshbzb/shehuibaozhang/zcwj/yiliao/. 


\section{Coloproctology Joe King Man Fan and Zhonghui Liu}

8. Beijing Municipal Commission of Development and Reform. Charges of medical services. [Internet]. Beijing: Beijing Municipal Commission of Development and Reform; [cited 2017 Dec 8]. Available from: http://service2.bjpc.gov.cn/bjpc/mediprice/MedicalService1.jsp\#top.

9. Zero surcharge for medications [Internet]. [cited 2017 Dec 8].
Available from: http://www.gov.cn/guowuyuan/2018-01/05/content_5253309.htm.

10. WeChat [Internet]. Shenzhen (China): Tencent Inc.; 1998-2018 [cited 2017 Dec 8]. Available from: https://weixin.qq.com/.

11. Three fames project [Internet]. [cited 2017 Dec 8]. Available from: http://www.szhfpc.gov.cn/ztzl//smgc/. 